\title{
Pesquisa e(m) Artes: uma reflexão sobre a interpretação musical e investigação
}

\author{
Eduardo Lopes (Universidade de Évora, Departamento de Música, Évora, Portugal)
}

el@uevora.pt

\begin{abstract}
Resumo: A entrada das artes performativas na academia universitária tem levantado questões sobre a relação entre pesquisa tradicional e as áreas artísticas de vertente prática. Na sequência de pesquisa recente sobre este assunto e partindo do contexto do processo de avaliação do desempenho dos docentes da Universidade de Évora - Portugal, este artigo apresenta uma reflexão sobre o posicionamento da performance artística na academia, em especial do que poderá ser pesquisa sobre prática musical. Propõem-se também que para além da pesquisa em arte/música, o valor intrínseco do conhecimento artístico deverá, por si só, valer o lugar das artes dentro das universidades.

Palavras-chave: Artes Performativas; Pesquisa em Artes; Música; Musicologia.
\end{abstract}

Research and/ in Arts: a reflection on musical interpretation and research

Abstract: The opening of higher education institutions to the performing arts has led to continuous discussion about the relation between traditional research and the practical nature of the arts. Following recent research on this subject and the context of the process of faculty evaluation at the University of Évora - Portugal, this article presents some thoughts about the position of performers in the academy, especially of what could be considered research on music performance. It is also proposed that besides the actual possibility for research on music performance, the intrinsic value of artistic knowledge should, in itself, be worth its place within higher education.

Keywords: Performing Arts; Artistic Research; Music; Musicology

\section{Introdução}

Sendo músico profissional há mais de trinta anos - e a profissão de músico provavelmente existe desde que alguém mostrou interesse em ouvir música -, não me deixa de espantar que de geração em geração de músicos, reclama-se continuamente pela aceitação desta profissão por parte da sociedade. Nos dias de hoje, as redes sociais apresentam regularmente comentários relatando ou reclamando situações em que a atividade profissional de músico foi ignorada ou desconsiderada por algum setor da sociedade (e.g. cachets insultuosos; más condições de trabalho; ignorância generalizada sobre o grande esforço pessoal que incorre da atividade). Por outro lado, cada vez mais o consumo e prática de música torna-se de fácil e transversal acesso a todas as culturas, fruto da rápida comunicação e transmissão de bens e conhecimento da sociedade contemporânea. Aqueles de nós que ainda viveram a "pré-história" da idade da comunicação (pré-computadores pessoais; internet; celulares), lembrar-se-ão muito bem da dificuldade que havia em ter acesso a um determinado disco; livro técnico de ensino; uma aula de música; e mesmo para adquirir algum instrumento ou acessório musical mais específico. Hoje em dia, tudo isso, se não estiver fisicamente perto de onde nos encontramos, está seguramente a um click de distância, bem como economicamente muito mais acessível relativamente ao passado próximo. É então por isso, que para além de todos nós consumirmos música de alguma forma, também conhecemos diretamente alguém que regularmente a pratica (uma outra imagem que me ocorre é a regularidade com que vemos alguém nas ruas das nossas cidades a transportar algum tipo de instrumento no seu estojo. Algo que há umas décadas atrás não era muito comum observar).

Também é do conhecimento de todos vários exemplos de artistas e músicos que se encontram entre as pessoas economicamente mais abastadas do mundo, demonstrando alguns destes, vidas de luxo e, por vezes, de grande extravagância financeira. No entanto, e como referido acima, parece existir genericamente uma (inicial?) desconfiança da possibi- 
lidade e talvez sucesso da profissão de músico. De uma forma similar aos músicos, a atividade de desportista parece também sofrer da mesma condição. Não será assim de todo estranho apontar uma certa correlação entre esta percepção de "menos valia profissional" e a "alta componente lúdica e de entretimento" que é integral às artes e música. Sem querer negligenciar outros aspectos de um mosaico complexo, é exatamente esta aparente dicotomia entre o "perfil lúdico" e o que é "sério" e profissional, que o músico e a sociedade constantemente negociam.

A motivação para este texto adveio do artigo seminal e polêmico ${ }^{1}$ de John Croft (2015) "Composition is Not Research", e da reflexão que tem sido feita nos órgãos científicos da Universidade de Évora (UÉ), respeitante ao processo de avaliação plurianual interna dos seus docentes ${ }^{2}$. Adotada já há alguns anos, esta avaliação centra-se nos três parâmetros habituais e pilares da atividade docente universitária (LOPES, 2015): Ensino, Pesquisa e Extensão. A estes três, a UÉ decidiu incluir um quarto parâmetro: a sempre laboriosa Gestão Universitária. Para melhor refletir as especificidades da UÉ e das suas unidades orgânicas e perfis de docentes, nalguns dos quatro parâmetros foram adicionadas outras possíveis atividades e desempenhos. Assim, para a avaliação docente na UÉ são então considerados os seguintes parâmetros:

\section{Vertente Ensino}

2. Vertente Pesquisa, Criação Cultural e Artística

3. Extensão Universitária, Divulgação e Valorização do Conhecimento

4. Vertente Gestão Universitária e Outras Tarefas

Após alguns anos com esse modelo em funcionamento foi questionada a presença da Criação Cultural e Artística no mesmo parâmetro da Pesquisa. Esta questão não levantaria grande (ou necessária) discussão se esse posicionamento não incluísse uma determinada e significativa cota de avaliação docente e inerente paridade/similitude entre Pesquisa e Criação Artística. Ou colocando as coisas de uma forma muito pragmática: um artigo científico numa revista com revisão por pares terá o mesmo "valor" que um concerto ${ }^{3}$ ou composição?

\section{Pesquisa}

Nesse contexto, não se poderá deixar de considerar que a questão do que é pesquisa em artes também se coloca, devido à entrada do ensino de música (prática) nas instituições de ensino universitário, que, como referido acima, contempla em grande medida a vertente de pesquisa. Na caminhada ao longo dos séculos com o intuito de valorizar a Música em total paridade com as outras atividades da humanidade, os músicos almejaram também incluir a sua área nas instituições de mais alto nível de conhecimento. Até recentemente, em Portugal (um pouco mais cedo noutros países), a música era ensinada em instituições próprias e de certa maneira isoladas do ensino geral. A música tinha, assim, o seu ensino centrado em Conservatórios e Academias, que certificavam graus específicos em música, desde iniciação até graus avançados, num contexto quase exclusivo à música. A vontade que os músicos sentiram em terem os seus graus acadêmicos devidamente reconhecidos e equiparados aos demais da sociedade, resultou que o ensino superior de música passasse a ser lecionado nos institutos politécnicos ${ }^{4}$ e universidades, sendo assim, conferidos graus idênticos a outras áreas de conhecimento (bacharelato, licenciatura, mestrado e doutorado). Aliás, eu próprio, há cerca de 20 anos, quando iniciei estudos de doutoramento em música, 
fui questionado por amigos de outras áreas como se efetuava um doutorado em música ${ }^{5}$ aludindo evidentemente à prática musical e pesquisa.

E, assim, chegamos nos dias de hoje à reflexão sobre se um momento artístico performativo, por si só, poderá ser considerado um trabalho de pesquisa.

Para começar a abordar esta questão é inevitável tentarmos compreender o que é pesquisa - o que faz e para que serve. Considerando a definição da Organization for Economic Co-operation and Developing (OECD, 2015), pesquisa "comprise creative and systematic work undertaken in order to increase the stock of knowledge - including knowledge of humankind, culture and society - and to devise new applications of available knowledge."

O que é interessante observar nesta definição, é que para além da menção comum ao trabalho metódico e científico com o intuito de criar novo conhecimento e aplicações (e inerente disseminação) deste, é a menção à criatividade. Com esta menção, evita-se, assim, o assumir de qualquer dicotomia entre trabalho metódico e trabalho criativo, favorecendo também a validade de resultados baseados em "epistemologias menos positivistas". Um outro apontamento importante, é o sublinhar da importância do conhecimento sobre a Humanidade e seus contextos culturais e sociais. Também, através dessa menção, abre-se o espectro daquilo que pode ser reconhecido como conhecimento relevante; para além do meio físico, inclui-se, assim, outras áreas tradicionalmente assumidas como "menos científicas". Desta maneira, parece apontar-se Pesquisa como uma atividade de cerne humana, transversalmente presente no nosso quotidiano, e que nos acompanha do passado para o presente, preparando de certo modo o futuro.

Não sendo, por vezes, imediatamente claro, qualquer ação de pesquisa segue, de uma forma geral, o seguinte modelo:
a. a Questão que se coloca
b. o Contexto em que se insere
c. os Objetivos
d. as Metodologias de trabalho
e. os Resultados obtidos
f. Divulgação

\section{Reflexões}

Consideremos o possível funcionamento deste modelo para um exemplo bastante simples do nosso quotidiano. Imaginemos que são 12h30min da tarde e que alguém se encontra na zona do Cais do Sodré, em Lisboa, e com uma natural sensação de fome. Instintivamente ou não, essa pessoa sentirá uma necessidade de resolver esta questão (problema). Saberá certamente o contexto desta questão quando surja a fome; o seu porquê; o que outros fazem para a resolver; bem como insucessos de certas medidas, como por exemplo uma má escolha de restaurante ou 'prato-do-dia'. Com este conhecimento, os seus objetivos seriam claros, por exemplo: encontrar um restaurante localizado a pouca distância, com comida de qualidade que servisse o propósito de a/o alimentar, mas também sem que esta fosse demasiadamente, dificultando as tarefas que teria que efetuar pela parte da tarde. Assim, esta pessoa começa a desenvolver uma metodologia que lhe permita explanar bem a situação, da mesma forma que a correlação das diferentes possibilidades - prós e contras de uma determinada decisão. Por exemplo, tendo vontade de comer Sushi no seu restaurante preferido, que fica localizado na Avenida 5 de Outubro, a uma distância considerável de onde se en- 
contra, o que teria que fazer para ajustar este tempo despendido. Ou, por outro lado, considerando o excelente restaurante de Tapas sito na Rua da Prata - sendo mais perto, sem oferecer ementa de Sushi e até mais dispendioso. Assim como outras dezenas de possibilidades e variações. Com todos os resultados apurados esta pessoa poderia assim decidir (divulgar) a melhor solução encontrada para a questão da fome que a/o assolava. Considerando a definição da OECD, o processo descrito acima apresenta genericamente algumas ressonâncias de pesquisa. Deste modo, poderemos então efetivamente considerá-lo pesquisa?

Antes de elaborar mais, darei um outro exemplo de talvez ainda mais fácil compreensão. Imaginemos agora um hipotético e estranho mundo ${ }^{7}$ em que só existiam copos de plástico e de um só tamanho. Um certo dia, um oleiro chegou à conclusão que talvez pudesse fazer copos de barro e que estes até poderiam ter algumas vantagens em relação aos antigos copos de plástico. Assim, e para abreviar:

- Questão: como fazer copos de barro de diferentes tamanhos.

- Contexto: a existência de copos de um só tamanho e de plástico, não podendo ser feitos de outra forma; bem como outras tentativas de os produzir com outros materiais e técnicas não foram bem sucedidas.

- Objetivos: fazer copos de barro de diferentes tamanhos que possam resistir a um maior espectro de temperaturas dos seus conteúdos.

- Metodologias: encontrar a argila ideal para a forma a desenvolver; procurar a mistura ideal com água que facilite a moldagem do objeto; definir várias velocidades da roda de oleiro que facilite uma nova técnica de mãos para a moldagem das peças; procurar a madeira e temperatura ideal do forno para a cozedura do barro; eventual decisão sobre as melhores tintas para pintar as peças.

- Resultados: comprovação do desenvolvimento de excelentes copos de barro de diversos tamanhos, que podem receber líquidos quentes e frios para um espectro de temperaturas superiores aos de plástico.

- Divulgação: à comunidade através de comparação das vantagens dos copos de barro em relação aos de plástico.

Na gênese da definição de pesquisa proposta pela OECD, bem como inerente ao modelo funcional de pesquisa acima apresentado, está obviamente também considerada uma atitude de reflexão crítica por parte de quem faz pesquisa. Será então também esta "crítica” de um determinado contexto e consequente "reflexão" que alavancará conhecimento de uma determinada questão, fomentando desta forma o avanço da área relacionada. Esta necessária atitude de reflexão crítica num processo de pesquisa, aponta, na sua essência, o investigador como consciente da sua atividade de investigação.

Se atividades de teor prático como as descritas acima (em que o ato de alimentação é também uma necessária praticalidade), claramente apresentam alguns processos de pesquisa, poder-se-á notar que o primeiro exemplo descrito não se apresenta como uma reflexão crítica por parte da pessoa em questão. Nesse rudimentar exemplo, e apesar de alguma metodologia estar presente para facilitar a melhor decisão, os resultados estão revestidos de experiência(s) do passado e descontextualizadas (e.g. neste caso nada garante a contínua qualidade de um determinado restaurante), e não seguindo necessariamente um número elevado de opções e sua correlação. Uma outra questão neste exemplo, prende-se com a divulgação de resultados. Como acima apontado, um dos princípios de pesquisa é a divulgação de resultados de forma a que estes possam contribuir para o avanço de qualquer atividade e/ou área. No exemplo dado, a pessoa tomaria a sua decisão e provavelmente guarda- 
ria a informação para ela própria; e mesmo que divulgasse mais tarde os bons resultados da escolha para a situação em que se encontrava, estes poderiam não ser adequados ao novo contexto de um outro indivíduo.

No entanto, tendo em conta que este exemplo tem ressonâncias de processo de pesquisa, como é que este poderia ser pesquisa? Sem querer entrar em muito detalhe e, também, por não querer, neste momento, sugerir quaisquer projetos de pesquisa, poder-se-ia enquadrar a questão do exemplo acima num projeto de pesquisa de postura "Research into Practice” (pesquisa sobre práticas). Segundo Schippers (2007), "Research into Practice" é pesquisa feita por terceiros que parcialmente usa conhecimento inerente de quem pratica algo. Deste modo, um grupo de investigadores de diferentes áreas poderiam coletar diferente informação empírica de um número alargado de indivíduos na mesma situação da pessoa mencionada no exemplo; reunir toda a informação sobre restaurantes da área; distâncias, etc.; e desenvolver uma aplicação para dispositivos móveis (app), que permitisse a alguém na situação exposta, tomar a melhor decisão de acordo com a sua vontade e necessidade.

O segundo exemplo já demonstra uma clara consciência de um processo de procura e realização de algo. Neste caso, temos um practitioner especializado numa área e com conhecimentos teóricos que lhes permitem a resolução (ou descoberta) de um problema e criação de algo novo, contribuindo assim para a sociedade. Assumindo então que o ceramista em questão é capaz de eficientemente divulgar e disseminar a sua descoberta de uma forma clara e funcional à sociedade, temos então aqui um caso de "Practice as Research" - que, segundo Schippers (2007), inclui reflexão crítica sobre um problema com pretensão consciente de divulgação clara de resultados.

Parece, dessa forma, óbvio que pesquisa incluindo ou derivada de atividades altamente práticas, pode encaixar perfeitamente nos modelos de pesquisa corrente, desde que assuma conscientemente o que pretende fazer, ou seja, crítica ou resolução de uma questão/ problema, contribuindo para o conhecimento. Mas, para enfocarmos um pouco mais este artigo naquilo a que ele se propõe abordar, vejamos o caso da interpretação musical.

\section{Pesquisa e Interpretação Musical}

A interpretação musical e a música em geral existem desde o início dos tempos e têm uma função social e/ou artística. Enquanto a segunda infere na música valores intelectuais derivados de uma percepção aural relativa (e por vezes até aleatória) de alguns dos parâmetros físicos do som, a primeira assume a música como acessória a uma outra atividade. De qualquer forma, e nos dois casos, a realização de um segmento musical está sempre, e na sua base, na percepção deste por algum ouvinte (quer seja um espectador ou mesmo o próprio músico). Assim, e não considerando o projeto Modernista da objetificação da música, o resultado de qualquer interpretação de um segmento musical não é sempre o mesmo, estando dependente de um conjunto alargado de variáveis de contexto, que inclui necessariamente a percepção individual de cada ouvinte - e que na sua essência é isso que acaba por definir música e interpretação musical como Arte. Para além de questões de método, como as acima descritas, a "normal" interpretação musical e respectiva recepção não se enquadram em pesquisa por, e logo à partida, a sua realização e recepção não resultar em respostas/resultados claros e óbvios para todos. O que um ouvinte percepciona não é necessariamente similar à experiência de um outro quando exposto ao mesmo segmento musical.

A interpretação musical também pode ser e/ou contribuir para pesquisa. De seguida, irei apresentar dois exemplos do que pesquisa em interpretação musical poderá ser, ou, 
por outro lado, como pesquisa pode estar incluída na interpretação ${ }^{8}$.

Há algum tempo atrás participei num concerto inserido numa formação de octeto que interpretou música do gênero jazz. Neste gênero musical, é frequentemente assumido um crescendo de energia durante cada solo. Nesse contexto, os diferentes músicos realizam esse contexto para o solista através de vários recursos musicais que aumentam não só a densidade da estrutura acompanhamento, bem como a própria dinâmica musical, apoiando o solista na sua narrativa até ao culminar da sua intervenção. Consequentemente, sempre que muda o respectivo solista, assume-se um relaxar e uma dinâmica menos densa de forma a iniciar o novo solo, esperando assim o natural desenvolver da nova narrativa solística. Entre outras, uma das formas mais eficientes de criar este abaixamento de dinâmica na bateria é interpretando estruturas rítmicas mais espaçadas, fazendo uso de pausas ou notas longas, criando uma estrutura rítmica menos densa, dando assim, uma sensação de acalmia e certo relaxamento, sem perder a personalidade dos padrões rítmicos intrínsecos a um determinado tema e contexto musical. Durante o concerto em questão, um dos temas provou ser tecnicamente difícil para o baixista - instrumentista que genericamente tem uma função similar e em consonância com o baterista. A certa altura na secção de solos, o baixista aparentando estar "perdido" na estrutura, começou a interpretar padrões musicais incertos, que começavam a tornar toda estrutura musical bastante inconstante. Um dos instantes em que isso foi mais notório, foi exatamente na transição entre solistas, em que se pretendia, como acima referido, um abaixamento da intensidade rítmica.

Através da minha experiência como intérprete musical, sabia que se eu iniciasse na bateria o esperado relaxamento rítmico através de estruturas mais espaçadas, isto junto com a aparente incerteza rítmica do baixista, poderia desequilibrar todo grupo, criando insegurança em todos, algo que seguramente resultaria numa catástrofe musical. Desse modo, optei por manter um padrão rítmico, o mais completo possível, compensando a "falta" momentânea de baixista, utilizando somente o recurso de criar uma dinâmica sonora bem mais baixa como ferramenta para a percepção de inicio de novo solo ${ }^{9}$. Esse momento musical de ajuste numa interpretação devido a um problema que surgiu, não foi perceptível para todos os músicos e calculo que não terá sido para a esmagadora maioria da audiência. Do ponto de vista artístico, este momento terá sido recepcionado como qualquer outro na peça, demonstrando uma atitude orgânica de música ao vivo, em que momento-a-momento a música vai sendo realizada de acordo com as expectativas criadas pelos instantes anteriores - algumas vezes resolvendo as expectativas, outras não - em que a percepção do que aconteceu do ponto de vista musical ficou no âmbito de cada ouvinte. No entanto, este momento poderá também ser resultado ou servir de material de pesquisa. Pensemos então numa gravação deste concerto e do momento em questão. Parecerá óbvio que, por si só, esta gravação não serve como exemplo de pesquisa. O que foi realizado, para além de ser fruto da minha experiência, foi decidido no momento. Na realidade, poderia até ser observada outra solução, pois eu não tive tempo de considerar num contexto mais alargado o que poderia ter resultado melhor. Do mesmo modo, aquele momento (ou sua gravação) não serve necessariamente de meio de disseminação desse conhecimento, pois quem a ouve pode não identificar e percepcionar o que estava a ser questionado, bem como o inerente resultado. No entanto, um pesquisador poderia desenvolver alguma investigação sobre o concerto e esse determinado momento. Esta pesquisa poderia, por exemplo, refletir sobre a densidade de estruturas rítmicas e diferentes equilíbrios possíveis, considerando os vários parâmetros envolvidos na construção de determinado padrão rítmico. Os resultados poderiam ser uma lista dos padrões rítmicos para a bateria que funcionassem em diferentes contextos, fornecendo diferentes panorâmicas de 
acordo com o pretendido. Desta maneira, para o final de um solo num gênero musical de bossa nova - que incluiu na bateria colcheias contínuas - poderia propor-se como um possível padrão para decréscimo de intensidade, mas sem o risco de perder a certeza rítmica do grupo, a realização de um padrão de semínima/duas colcheias (ou duas colcheias/semínima) continuamente. Também, poder-se-ia adiantar que a diferença entre o primeiro e o segundo padrão, é que o primeiro tende ainda a ser mais estável que o segundo. Para chegar a estas conclusões poderíamos realizar experiências do foro empírico através de gravações e avaliação de resultados, bem como literatura relevante sobre este assunto já publicada (LOPES, 2003). Todos os resultados finais poderiam então ser apresentados em conferências ou publicados para disseminação sobre a forma de artigo ou livro, relevantes para áreas do conhecimento artístico como a formação musical, teoria da música, e a própria interpretação musical.

Um outro exemplo são as famosíssimas interpretações de guitarra elétrica com arco (de violino ou violoncelo) pelo músico britânico de rock Jimmy Page. A utilização por Page de um arco na guitarra elétrica em dois temas do disco "Little Games", da banda Yardbirds de 1967, e mais tarde em 1969, já com os Led Zeppelin no tema "Dazed and Confused", juntamente com a utilização desta técnica por ele próprio em concertos ao vivo para dezenas de milhares de espectadores, foi sem dúvida um dos grandes momentos para a história da guitarra elétrica. Segundo uma entrevista de Page (2012) para a CBS, a ideia de tocar guitarra com arco foi-lhe sugerida alguns anos antes das gravações em questão, por um músico de instrumento de arco que o indagou se alguma vez tinha pensado na possibilidade de tocar guitarra elétrica com arco.

Page pouco mais referiu publicamente sobre o que o levou a utilizar o arco na guitarra, ou mesmo a própria técnica utilizada na sua realização. Aparentemente para Page, o acaso e a sua curiosidade por timbres pouco utilizados fez com que "descobrisse" esta interessante possibilidade para a guitarra elétrica. Juntamente com os inúmeros concertos realizados (e inerente disseminação), esta “descoberta” de Page não se me apresenta por si só como um exemplo de pesquisa. Page, efetivamente um grande especialista da guitarra elétrica, através de uma imensa experiência junto do instrumento e natural curiosidade por tudo que envolve música, terá chegado a esse resultado numa espécie de processo de observação instintiva do que rodeia o seu contexto de atuação - obviamente juntando alguma característica individual de quem é exímio executante de uma determinada área. O que se assinala aqui é que, naturalmente, um exímio praticante de uma determinada área terá conscientemente desenvolvido e encontrado (novos) processos que lhe servem um propósito - e isto, por si só e como já referimos acima, não reflete necessariamente a pesquisa.

Pesquisa sobre aquilo que Page apresenta nos seus concertos quando toca guitarra elétrica com arco, deveria pelo menos, e a título de exemplo, considerar a reflexão sobre o contexto genérico da utilização do arco na guitarra. Apesar de Page nunca ter referido que foi o primeiro músico a utilizar essa técnica, ao pesquisarmos um pouco sobre este assunto, começamos a encontrar relatos de que Eddie Philips, um outro guitarrista Britânico contemporâneo de Page, teria já utilizado a técnica antes dele, tendo mesmo gravado um disco em 1966 com partes de guitarra elétrica com arco - um ano antes dos aclamados discos dos Led Zeppelin. Deste modo, qualquer pesquisa sobre Page e a sua utilização do arco na guitarra, não poderá deixar de lado essa reflexão. Noutra linha de pensamento crítico, poder-se-ia também, refletir como a experiência e práticas do passado abordavam também a utilização de um arco em instrumentos de corda dedilhada. Segundo Schneider (2015, p. 113), como forma de resolver a natural falta de sustentação da duração dos sons nas guitarras, já 
em 1823 o luthier austríaco Johann Stauffer desenvolveu um protótipo de guitarra que tinha alguma curvatura na escala no braço, permitindo assim, a utilização de um arco, resolvendo deste modo a questão da sustentação das notas. Como acima, a pesquisa sobre o caso de Page não poderá também negligenciar este momento, pois não sendo deste modo, não haverá real avanço para o conhecimento da área - caindo numa espécie de vortex de esquecimento do conhecimento já adquirido.

Mas podemos também pensar no exemplo de possível pesquisa a jusante de Page e o seu arco na guitarra elétrica. Sem sombra de dúvida, a exposição mediática de Page, terá contribuído para a atenção na guitarra elétrica e, consequentemente, o seu uso do arco. Schneider (2015) afirma que foi na década de sessenta que houve um ressurgimento do uso do arco como extensão da técnica de guitarra (acústica), dando como exemplo a peça de 1968 "Estampida" de Kröll. Para eventual futura pesquisa: teria o músico rock Jimmy Page influenciado compositores de outras áreas musicais a pensarem (novamente) no uso do arco numa guitarra?

\section{Considerações Finais}

Parece-me claro que um concerto ou apresentação musical não será por si só pesquisa. Uma performance artística poderá, e de fato muitas vezes inclui pesquisa e questões pertinentes para o avanço do conhecimento musical. No entanto, de uma forma genérica, o resultado artístico e a performance dificilmente poderão ser consideradas pesquisa.

Como referi anteriormente e como apontado por mim em Lopes (2016), muita pesquisa poderá ser feita em e sobre a performance musical. Obviamente, e para que isto aconteça, terá que haver uma vontade de fazer pesquisa seguindo alguns dos princípios do que pesquisa é, e para que esta serve, conforme acima abordado. Considerando que a Arte e a Pesquisa estão constantemente presentes na história da Humanidade, será assim o ato de efetuar conscientemente qualquer uma delas (ou as duas), o que ulteriormente distingue a Arte da Pesquisa.

À medida que eu chego ao fim desta reflexão, não deixo de notar a ironia do pensamento por detrás daquilo que levará qualquer Artista a querer ser considerado pesquisador. Reconhecida desde sempre, a especial nobreza em alguém ter a possibilidade de ser Artista (músico, ator, pintor, etc.), é tão única e específica que não necessita de algo mais para se afirmar como relevante em qualquer patamar da sociedade - desde a mais simples das funções sociais do artista, até à sua inclusão em instituições de alto conhecimento. Não obstante, entende-se facilmente que a entrada das artes performativas e dos seus practitioners na universidade, incorre numa necessidade de assumir estruturas que não são necessariamente a mesma coisa, e que incluem até vivências muito diferentes.

De forma a que a universidade salvaguarde questões de justeza de posicionamento das diferentes áreas dentro das suas portas, deverá então assumir a importância específica de cada especialidade. Desta maneira, poderá mais facilmente fomentar o que cada área tem de específico e melhor, contribuindo cada uma na sua esfera de ação para o avanço comum. Retomando agora a questão da avaliação docente em instituições de ensino superior, acredito que a atividade artística - Criação Cultural e Artística - não deverá ser posicionada juntamente com Pesquisa, mas sim numa outra rúbrica, como, por exemplo, a Extensão, ou outra até especialmente criada para o efeito. Portanto, questões irreais de comparações e valorizações relativizadas de atividades bastante distintas deixarão de existir, promovendo assim uma salutar coexistência para o avanço e progresso de todos. 


\section{Notas}

1 A título de exemplo ver as respostas a este artigo por parte de Camden Reeves "Composition, Research, and Pseudo-Science: A response to John Croft” e de Ian Pace "Composition and Performance Can Be, and Often Have Been, Research", bem como a resposta pelo próprio John Croft "Composing, Research and Ways of Talking”, artigos da revista Tempo, Volume 70, número 275, ano 2016.

2 Regulamento de Avaliação de Desempenho dos Docentes da Universidade de Évora, Despacho 1038/2011, Diário da República, $2^{\text {a }}$ Série - n. 8 - 12 de Janeiro de 2011

3 Acredito que na sua generalidade as questões de pesquisa abordadas neste artigo poder-se-ão aplicar à maioria das artes do espetáculo, como também outras expressões performativas em que o "objeto" final carece de uma realização por terceiros através da sua percepção - como por exemplo as artes visuais.

4 A inserção do ensino de música na estrutura de ensino Politécnico reconhecia a maior vertente prática da música e nesta estrutura de ensino não incluiria pesquisa. Recentemente, o próprio ensino Politécnico tem-se descaracterizado na sua essência aproximando-se ao ensino Universitário. Esta mudança de paradigma nestas estruturas de ensino superior parece-me ser ao momento uma discussão de teor político mais do que verdadeiramente organizacional e pedagogicamente refletido. Mas sendo o caso ao momento de os Politécnicos caminharem também para a prática de pesquisa, assume-se similitude entre estas estruturas. Por outro lado, o inverso se poderá dizer com a entrada das artes práticas nas Universidades. Mas para este artigo deixemos por agora de fora esta também complicada realidade.

5 Há altura e para evitar subsequente discussão que poderia levar a questões que eu próprio não estaria suficientemente confiante para responder fazia-me valer da área da minha especialização, Teoria da Música, e em especial do termo teoria, apresentando assim uma similitude entre o doutoramento em música e processos de pesquisa de outras áreas - i.e., observo a prática e reflito e avanço conhecimento sobre "teorias"; e, de certa maneira, isto resolvia a discussão.

6 "implica trabalho criativo e sistemático com o fim de aumentar a quantidade de conhecimento - que inclui conhecimento sobre a raça humana, cultura e sociedade - e para criar novas aplicações do conhecimento existente" (tradução do autor).

7 Talvez um mundo idêntico àquele descrito no livro de 1963 de Pierre Boulle "La Planète des Sieges" e amplamente divulgado na série de filmes "Planet of the Apes", em que uma civilização é completamente apagada (fisicamente e da memória), em que tudo começa de novo com a exceção de alguns resíduos da civilização anterior.

8 No que diz respeito aos exemplos de metodologias contemporâneas para a pesquisa em interpretação musical, poderá ser consultado o artigo, "Para uma Ontologia da Pesquisa em Música no Séc. XXI" (LOPES, 2016)

9 Felizmente, este tema musical durou poucos minutos mais.

\section{Referências}

CROFT, J. Composition is Not Research. TEMPO, v. 69, n. 272, p. 6-11, 2015.

Lopes, E. Just in Time: towards a theory of rhythm and metre. 2003. 239f. PhD (Thesis) - Faculty of Arts - University of Southampton, Southampton, UK, 2003.

LOPES, E. O Ritmo e a Improvisação Musical como Veículo para a Extensão Universitária. Revista da Universidade Federal de Goiás, Ano XV, n. 16, p. 9-22, 2015.

LOPES, E. Para uma Ontologia da Pesquisa em Música no Séc. XXI. In: ZURBACH, Christine (Coord.). Perspectivas da Pesquisa e(m) Artes - II. Évora: Universidade de Évora, 2016.

OECD. Frascali Manual. 2015. Disponível em: <http://www.oecd.org/sti/inno/Frascati-Manual. htm\#data>. Acesso em: 29 ago. 2016.

PAGE, J. Jimmy Page On The Violin Bow: 'Whatever Squeaks I Made Sort Of Intrigued Me'. 2012. Disponível em: <http://wcbsfm.cbslocal.com/2012/10/01/jimmy-page-on-the-violin-bow-whatever-squeaks-i-made-sort-of-intrigued-me/>. Acesso em: 29 ago. 2016.

SCHNEIDER, J. The Contemporary Guitar. Lanham, Maryland: Rowman \& Littlefield Publishers, 2015.

SCHIPPERS, H. The Marriage of Art and Academia: Challenges and Opportunities for Music Research in Practice-based Environments. Dutch Journal for Music Theory, v. 12/1, p. 34-40, 2007. 
Eduardo Lopes - Efetuou estudos de bateria jazz e percussão clássica no Conservatório Superior de Roterdão (Holanda). É licenciado pela Berklee College of Music (EUA) em Drum Set Performance e Composição com a mais alta distinção (Summa Cum Laude). É doutor em Teoria da Música pela Universidade de Southampton (Reino Unido), tendo feito Pós-doutoramento no Instituto Superior Técnico (Lisboa). Em 2015 recebeu pela Universidade de Évora o mais alto título acadêmico português: Agregado em Música e Musicologia. Ao longo da sua carreira recebeu vários prêmios e bolsas de estudo nacionais e internacionais. Atua regularmente com os mais relevantes músicos portugueses e artistas internacionais de renome, tais como: Mike Mainieri (Steps Ahead); Dave Samuels (Spyro Gyra); Myra Melford; Susan Muscarella; Kevin Robb, Phil Wilson; e Bruce Saunders. Gravou vários CDs, alguns dos quais em seu próprio nome. Apresentou-se em concertos em Portugal, Espanha, França, Holanda, Inglaterra, Escócia, Brasil, Japão e EUA. É autor de vários artigos e textos sobre a problemática da interpretação musical, teoria da música, jazz e ensino de música. Lecionou na Universidade de Southampton no Reino Unido e na Escola Superior de Música e Artes do Espetáculo em Portugal. De 2012 a 2016 foi diretor do Departamento de Música da Universidade de Évora. Entre setembro de 2016 e agosto de 2017 foi Professor Titular Visitante na Escola de Música e Artes Cênicas da Universidade Federal de Goiás (EMAC/UFG) no Brasil. No momento, é professor associado com Agregação do Departamento de Música da Universidade de Évora. 